\title{
Organizational Contexts of Professional Work in Third Sector
}

\author{
Ana Paula Marques \\ Associate Professor, PhD - Department of Sociology (University of Minho/Portugal) \\ Senior Researcher of Research Centre for the Social Sciences (CICS/UM) \\ amarques@ics.uminho.pt \\ Telmo H. Caria \\ Department of Economy, Sociology and Management, \\ University of Trás-os-Montes and Alto Douro (UTAD), \\ tcaria@utad.pt
}

\section{Doi:10.5901/mjss.2013.v4n9p558}

\section{Abstract}

Recent developments in professional practice in organizations of the Third Sector in Portugal show a significant pressure regarding the adoption of management models which are close to the logic of the New Public Management (NPM). Our basic hypothesis will consider to what extent these trends of transformation in the governance models, based on increased flexibility of working relationships, fostering both professional instability and control, are articulated with the requirements of trust, initiative and improvisation of professional practice. Based on main results gathered on ongoing project "SARTPROknowledge, Autonomy and Reflexivity: Professional work in the Third Sector" (PTDC/CS-SOC/098459/2008), this presentation is structured from the relevant analytical parameters in understanding the inter-professional changes and of the occupational structure and the result of the increasing heterogeneity of professional degrees in nearby areas, particularly in Social Sciences and Humanities. We will resort to structured interview data obtained of empirical work (interviews conducted to 63 professionals working in organizations of the Third Sector). Therefore, We will focus on: 1) organizational contexts of professional development (location, size, type of services, socio-demographic profile), 2) processes of domination/ rationalization in the daily professional work (increasing wage, stepping up the pace of work, variability of the organizational contexts of action, including teamwork and different composition), 3) non-linearity and homogeneity of processes of professionalization (vs. technicality. responsibility and management of teams, autonomy vs. fulfilling of goals and bureaucraticadministrative control).

Keywords: Third Sector; professional work; organizational contexts; graduates of social sciences.

\section{Introduction}

It is undeniable that in Portugal in recent decades, there has been an encouraging movement in the participation of civil society and civic organizations, in particular third sector organizations (TS) in creating innovative solutions adapted to different social realities. These have been conceptualized as organizational solutions "between" the state and civil society to better meet the principle of subsidiary - since the nineties advocated communitarian guidelines - and of decentralization of decisions appropriate to the locus of the social problems which aim precisely to a response.

The dynamics of these organizations are also an important professional field for many science graduates of the Social Sciences and Humanities in achieving their goals and/or mission of a social nature ${ }^{1}$. They are called the third sector organizations ${ }^{2}$, organizations providing welfare services, funded by the state, governed by policies and directives emanating from the state, but with administrative and managerial autonomy. In fact, it is organizations that operate on contractual and agency logic of programs and policies on protection and social welfare.

\footnotetext{
${ }^{1}$ At this point, the previous government in office has approved several measures to promote employment and combat social exclusion, such as: i) implementing the program of professional internships Inov- Social ii) Social Credit Line Plus, to support organizations of the social economy and the National Programme of Microcredit or facilitate the creation of cooperatives, with the process of "cooperative in time".

2 We know that the conceptual boundaries of what is meant by "third sector organizations" are being discussed theoretically and analytically without being able to assert the existence of a consensus on this matter. In any case, the advances in its conceptualization allow us to record some of the points of convergence that can temporarily accept this proposed definition.
} 
This paper is part of empirical research area on the work and knowledge of professionals in the third sector that in the current knowledge society, becomes important not only to face the complexity of social problems such as the transformations that register in the socio-organizational conditions and professional work. The recent changes in the content of professional work in these organizations are relevant to the demands of combinations of top-level scientific knowledge - which tends to be associated with a reflective-discursive skill (Caria 2005, 2008) - with the inclusion of technical knowledge eminently practical, adapted, tacit and subjective that develop in the context of everyday (inter)action - translating into reflective and practical skills (Caria, 2005, 2008). On the basis of those skills, the demand for autonomy and power in the cultural-symbolic and technical plans of the professionals in their daily work is assumed.

Besides this knowledge, we are witnessing a growing importance of "managerial" knowledge in the current division of labour, and converge to a political and organizational autonomy of professional work as the logical result of evaluation and quality that tend to spread in the current framework of action of these organizations (Caria, 2010; Svesson \& Evetts, 2011). The dimensions of reflexivity and empowerment of professional work in the third sector need further study and reflection, which constitute the main theoretical proposals to be detailed in the SARTPRO project - Knowledge, Autonomy and Reflexivity: Professional Work in the Third Sector ${ }^{3}$.

Privileging a comprehensive approach, with particular use of ethnography, focuses on the analysis of practices, identities and reflexivity in the work context, and where the methodological design of this project is based on several key steps, each with specific goals. For this presentation, only the preliminary results will be reported. We will resort to structured interview data obtained of empirical work of Phase I (November 2009 to October 2010) ${ }^{4}$ that consisted of the census of organizations and extensive analysis of the professional work of graduates in Social Sciences and Humanities (SC\&H) (interviews conducted to 63 professionals working in organizations of the Third Sector).

In this way, this paper is structured from the relevant analytical parameters in understanding the inter-professional changes and of the occupational structure and the result of the increasing heterogeneity of professional degrees in nearby areas, particularly in Social Sciences and Humanities. We will focus on: 1) organizational contexts of professional development (location, size, type of services, socio-demographic profile), 2) processes of domination/ rationalization in the daily professional work (increasing wage, stepping up the pace of work, variability of the organizational contexts of action, including teamwork and different composition), 3) non-linearity and homogeneity of processes of professionalization (vs. technicality. responsibility and management of teams, autonomy vs. fulfilling of goals and bureaucratic-administrative control).

\section{Organizational contexts of Professional work}

\subsection{Geographical location, size and type of services}

Of the 63 interviews, they are distributed by geographical area and size of the organization by considering the number of workers in comparative terms, as follows: in the area of Porto, organizational contexts tend to be medium-sized and specialized; in the area of Braga, medium size organizations and medium-large stand out, suggesting contexts with valences and diverse services; in the areas of Trás-os-Montes and Alto Douro (TMAD) contextual situations in terms of the size of organizations are presented and being more diverse, with the most significant extreme positions with regards to small, followed by the large size.

If, in terms of mission and service organizations at the beginning of their foundation they developed their activity in social services and local development, currently, the type of services developed in organizations presents themselves as fundamentally diverse. This reality seems more outlined in the area of TMAD, yet with a prevalence of organizations focusing on education and social solidarity, while the presence of mixed organizations is in the majority in the area of Porto, and all types of services are unquestionable in the case of Braga.

This organizational form is closely linked with the size in terms of human resources, although one can envisage

\footnotetext{
${ }^{3}$ Under the scientific coordination of Telmo H. Caria, this research project, funded by the Foundation for Science and Technology (PTDC/CSSOC/098459/2008), is based on a research partnership between three Portuguese university research centres, - CIIE - Faculty of Psychology and Educational Sciences - University of Porto, CICS - Institute of Social Sciences, University of Minho; CETRAD - School of Humanities and Social Sciences at the University of Tras-os-Montes and Alto Douro.

${ }^{4}$ In addition to Phase I, the empirical design presupposes making two more steps. In Phase II (January to June 2011), the formation of an exploratory panel of intensive analysis of professional work, carrying out a series of two interviews with 21 professionals inserted in teamwork took place. In Stage III (to be launched in September 2011), there will be a panel of intensive ethnographic analysis of professional work where the ethnographic work focuses on knowledge and skills in reflective and discursive practices of professionals (about 10 participants selected the previous step).
} 
that, depending on the territorial and socio-economic contexts in which organizations fall, one can see a trend or a certain specialized organizations or to a greater "need" to develop more heterogeneous organizations with different missions and services. In fact, if one assumes a declared classification of occupations, it is possible to confirm a significant association with their geographic deployment of third sector organizations: psychosocial and clinical predominance for the area of Porto, reinforcing the idea that it might be organizational contexts which tend to be more specialized. In the district of Braga, it is relevant to the incidence of educational and cultural activities. Despite the greater dispersion of professional activities in the zone of TMAD, there is a socio-economic dominance.

\subsection{Young multidisciplinary teams, principally female}

As for the socio-demographic profile of the professionals, $63.5 \%$ are aged between 30 and 39 years, and $27 \%$ are younger than this age range. The youths of this segment of manpower, which cuts across the three geographical areas under study, is associated with an overwhelming majority of female presence $(79.5 \%)$ and tend to be of younger ages, compared to their male peers. This is a major and important source of information that supports the growing trend of feminization in the last 15 years. This trend of targeting the area by the presence of gender in academic training in Portugal is also being felt in other Member States of the European Union. Indeed, the information from the professional group to which it belongs, here is understood as the identification of top-level academic training, certifies the relative importance of social workers (25.4\%) and psychologists (25.4\%), followed by a sociologist (12.7\%), managers/ economists (11.1\%) and other academic training with varied degrees of institutionalization, as educators, social educators and other graduates in social sciences and humanities (ex. philosophers, gerontologists). Their distribution by gender confirms these trends, although in a more detailed analysis by the scientific field, it is found both in educators ${ }^{5}$, whether the managers and economists, have an important presence of male workers. That is, despite being professional work carried out mostly by women, the diversity of social and human sciences, due to the development of training offered at institutions of higher education and professional insertions in the field of "social action" calling for multidisciplinary teams, may explain some of the key processes of the reconstitution of these work contexts and strategies of delimitation of the professional field. The issues will be explored further.

\section{Domination and rationalization in daily professional work}

\section{1 "Specialized" paths, wage and mobility constrained}

Also, considering the information relating to the length of professionals in SC\&H, it reinforces the idea of recent professionalization of these sector with the integration of professionals: less than 5 years (41.3\%), between 6 to 11 years $(46 \%)$, although there were those who claimed to be the organization for more than 12 years (12.7\%).

In terms of professional paths, it is important to note that half of the respondents had other professional experiences in other organizations. However, many of them had been active in organizations close to the third sector (ex. education, the elderly and children, vulnerable populations in socio-economic and psychological terms); many others played roles as trainers in vocational schools or in state school teaching; and only a few in consulting companies involving human resources. A significant part of these professional experiences resulted in contractual situations based on green receipts and/or fixed-term contracts (certain and uncertain) and traineeships.

The fact that, currently, we are experiencing a trend towards increasing wages by these organizations, will explain to some extent, these paths based on close working areas and characterized by certain constrained mobility. These modalities of contractual relationship - some more tenuous and other more structured - are likely to be confirmed with the interviewees. Fixed-term contracts (certain and uncertain), professional traineeships and "green receipts" are the dominant forms of contractual relationships between the beginning of their professional activity in the organization. Indeed, the use of flexible forms of employment such as fixed-term contracts (certain and uncertain) (49.2\%), and the conclusion of service contracts with workers (with green receipts) (19\%) has defined these professional paths. Also relevant are the contracts for traineeships (19\%) that do not imply a formal employment situation which allows the organization to provide human resources to carry out certain tasks/functions. For young graduates, in turn, the traineeships are an opportunity that in many cases can be translated to formalizing a working relationship later. In addition, many had the opportunity to do a traineeship - as we shall see ahead - which could explain these itineraries

\footnotetext{
${ }^{5}$ In addition, educators with training in science education are mainly in the area of Braga, compared to other geographical areas, which allows us to understand, largely, the relevance of training in this area by the University of Minho.
} 
focused on this type of organization.

Table 1. Evolution of mode of hiring professionals in SC\&H

\begin{tabular}{|c|c|c|}
\hline Contractual relationship & Beginning of activity (\%) & Currently (\%) \\
\hline Green receipts (independent workers) & 19 & 3,2 \\
\hline Fixed-term contract (certain and uncertain) & 49,2 & 38,1 \\
\hline Permanent contract (effective) & 4,8 & 57,1 \\
\hline No written contract (informal) & 1,6 & 1,6 \\
\hline Temporary contract & 1,6 & - \\
\hline Curricular traineeship & 19 & - \\
\hline Other situation & 4,8 & - \\
\hline 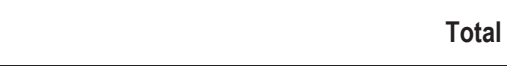 & $\begin{array}{l}100 \\
\text { (63) }\end{array}$ & $\begin{array}{l}100 \\
(63)\end{array}$ \\
\hline
\end{tabular}

Source: Structured interviews - SARTROP Project (2010)

But if it is certain that those forms of flexible employment are particularly relevant when they are recruited to the organization as there is a gradual stabilization of its relationship with the organization (which may not necessarily mean a stabilization of the work contract) 6 . Indeed, the contractual situation based on a permanent contract takes the most significant relative percentage (57.1\%), while those that remain with a contractual relationship determined by the end of their contract remains still significant $(38,1 \%)$. Also important seems to be the residual expression "green receipts" now faced at the beginning of the activity, which may explain the effectiveness of regulatory control of the classification of situations considered by law being subject to a contract of this nature. These results confirm the thesis concerning the generalization of precarious forms of employment in the recruitment of human resources in various sectors of economic activity advanced at which these third sector organizations do not escape.

Although the greater vulnerability of women is well-known in the incidence of more flexible employment contracts, compared to males, the truth is that this definition of the dimension of precariousness - since other dimensions have to be called - does not appear to be a valid expression of this sample. Certainly a significant part of its explanation lies in the fact that we are presenting a population of mostly female professionals in SC\&H. In any case, these professionals are subjected to a dynamic of precariousness, which contributes largely to the relevance of the "new" social and sexual division in the current third sector organizations. This will discuss to what extent the presence of the majority of female workers are a co-factor, explaining the processes of (de)professionalization of many occupations /professional activities arising.

It is also pertinent to note that this precarious nature carries with it increasing ambiguity in its conceptualization, since this tends to be defined only by reference to the contractual relationship. However, other dimensions must be called from those that refer to the degree of autonomy and working conditions, possibilities for development of knowledge and expertise, perspectives and perceptions of mobility and representations about the occupation. Moreover, in this sense it is closer to the dynamics of precariousness that Pinto (2006) sets out to describe in current trends, that we will move onto next.

\subsection{Hierarchical mobility and intensification of work pace}

From all respondents, the hierarchical position in the TS organization currently assumed varies between the Technician management and heads of service /department. Admittedly, when they entered, they assumed the position of graduate technician (69.4\%) overwhelmingly. Now, there is an important hierarchical mobility which allows us to foresee at the outset, the importance and recognition of the duties performed.

However, this professional recognition cannot be expressed identically for all groups involved in this study. Indeed, there has been a distinction between those who have a rank, with management and leadership functions, and declare only the top technical position. Sociologists, psychologists and managers/economists stand more proportionately in that rank, in opposition to social workers and educators, which tend to occupy lower positions.

${ }^{6}$ This question deserves special treatment, since many of the professionals may have closer relations with the organization and, for reasons of budget constraint; there remain some years without having a durable bond. In the context of Phase II, it may be possible to deepen this trend. 
This unequal involvement in the activity of the organization may be accompanied by other indicators mentioned above, such as the type of work relationship, but also by the number of hours worked per week and the time allocated for their activities. Thus, it appears that the average weekly hours of work falls short of 35 hours set at around almost 40 hours of work (average - 39.46, with breaks in between $17 \mathrm{~h}$ to $60 \mathrm{~h}$ ).

The allocation of working time in activities developed within the technical teams is representative of the consumption of "long time" by professionals. Those implemented within the organization, but without being directly related to work in teams also tend to require more "long and some time," may be indicative of significant changes in work content. The external activities remain, for all other activities, less consuming of work time.

Table 2. "Consumption" of time in professional activities

\begin{tabular}{|c|c|c|c|c|}
\hline & $\begin{array}{c}\text { Long } \\
\text { time }\end{array}$ & $\begin{array}{c}\text { Some } \\
\text { time }\end{array}$ & $\begin{array}{c}\text { Little } \\
\text { time }\end{array}$ & Total \\
\hline Activities in technical teams & 46,7 & 36,7 & 16,7 & $\begin{array}{c}100 \\
(60)\end{array}$ \\
\hline Activities inside the organization & 41,9 & 40,3 & 17,7 & $\begin{array}{c}100 \\
(62)\end{array}$ \\
\hline
\end{tabular}

Source: Structured interviews - SARTROP Project (2010)

Overall, the weight of the activities in technical teams, either in the organization and also outside the organization, appears very significant over the years. For $51.6 \%$ of professionals, their activities are all or nearly all performed in the context of technical teams to $27.4 \%$ about half of their tasks are performed in the context of technical teams to $21 \%$ of the activities integrated in less than half or only a small part in the context of teamwork technique. What emerges from this description is the significant weight of teamwork, being able to move that, on average, professionals participate in two technical teams. These teams comprise several other professionals, ranging from 2 to more than 7 people yet, constitute an average of 4 elements. It also notes the presence of the majority of female professionals in the composition of the teams, as well as the presence of other professionals in SC\&H. This variability of technical teams depends greatly on the size of the organization and, above all, the mission/type of services provided.

Table 3. Indicators of the variability of work contexts

\begin{tabular}{|c|c|c|c|c|c|c|}
\hline & & $\begin{array}{c}\text { Time in } \\
\text { organization } \\
\text { ( } \mathrm{n}^{0} \text { of years) }\end{array}$ & \begin{tabular}{|c|}
$\begin{array}{c}\text { Number of } \\
\text { weekly } \\
\text { working hours }\end{array}$ \\
\end{tabular} & \begin{tabular}{|c|} 
No. of \\
technical \\
teams in which \\
participate
\end{tabular} & $\begin{array}{l}\text { No. of elements } \\
\text { which includes } \\
\text { the main } \\
\text { technical team }\end{array}$ & $\begin{array}{c}\text { Number of } \\
\text { women in } \\
\text { leading } \\
\text { technical team }\end{array}$ \\
\hline \multirow{2}{*}{ Sociologists } & Average & 9,00 & 39,75 & 2,86 & 4,12 & 3,43 \\
\hline & St.d. & 4,243 & 3,845 & 1,773 & 2,100 & 1,813 \\
\hline \multirow{2}{*}{ Social workers } & Average & 7,19 & 41,38 & 2,06 & 4,56 & 3,50 \\
\hline & St.d. & 6,047 & 8,057 & 1,482 & 3,596 & 2,852 \\
\hline \multirow{2}{*}{ Psychologists } & Average & 5,62 & 37,56 & 2,00 & 6,12 & 4,25 \\
\hline & St.d. & 4,097 & 6,418 & 1,366 & 4,759 & 2,352 \\
\hline \multirow{2}{*}{ Educators } & Average & 7,33 & 39,50 & 2,50 & 5,00 & 4,00 \\
\hline & St.d. & 3,204 & 6,411 & 1,378 & 2,160 & 1,826 \\
\hline \multirow{2}{*}{ Social Educators } & Average & 8,00 & 36,00 & 2,17 & 4,67 & 3,67 \\
\hline & St.d. & 5,404 & 2,000 & 1,941 & 2,251 & 2,251 \\
\hline \multirow{2}{*}{$\begin{array}{l}\text { Managers } \\
\text { /Economists }\end{array}$} & Average & 6,14 & 38,86 & 2,57 & 4,40 & 2,80 \\
\hline & St.d. & 2,734 & 6,122 & 1,512 & ,548 & ,837 \\
\hline \multirow{2}{*}{$\begin{array}{l}\text { Others (ex. } \\
\text { philosopher, } \\
\text { gerontologist) }\end{array}$} & Average & 4,75 & 45,00 & 1,75 & 3,25 & 1,75 \\
\hline & St.d. & 4,500 & 10,801 & 1,500 & 1,708 &, 500 \\
\hline \multirow{2}{*}{ Total } & Average & 6,84 & 39,46 & 2,23 & 4,86 & 3,57 \\
\hline & St.d. & 4,618 & 6,732 & 1,487 & 3,365 & 2,249 \\
\hline
\end{tabular}

Source: Structured interviews - SARTROP Project (2010) 
Although there is not adequate room here to economize the text, the fuller exploitation of the dimensions of knowledge mobilized in a working environment that brings us to the questioning of what is meant by technical teams and, consequently, the types and nature of technical skills, is unquestionable that these work contexts indicate rearrangements in the contents of the intervention by professionals.

\section{Professionalization processes in the context of action}

\subsection{Transfer of knowledge: from collegiality and academic legitimacy}

The third sector organizations have been set up in a space par excellence for the transfer and application of academic qualifications, for the mobilization of technical and managerial knowledge in solving practical problems or inventing new solutions wherever required in the scope of team activities in technical and/or managerial positions. Thus, these hierarchies or classifications of knowledge can shed some light on the guidelines and present interests in terms of professional groups. To what extent is the opposition between knowledge certificates maintained and reinforced in everyday work in multidisciplinary technical teams? Or should we not be talking about the opposition of knowledge tout court in the new technical and organizational contexts? Rather, it should be talking about demands for autonomy and reflexivity in the contexts of work that brings us to the development of knowledge to constantly adapt to work or rehabilitation, acquisition of properties with ethics and behaviour consistent with the structures and logical functioning of the missions and goals of the organization?

The organizational models of work statements have been identified as threatening factors of the legitimacy of collegiality and professional activity, precisely because they introduce new logics of management and commercialization of these organizations. We have seen that these trends require further in-depth interviews and direct observation of everyday work provided for in the later stages of this work. It is also possible, in this paper to analyze the motivational structure of access to the profession and its identity references as to the realization that the respondents of the adequacy of academic training and their correspondence with the activities and functions performed 7 .

Although relatively young in age and in terms of holders of a substantial professional experience, as performed in the context of TS organizations, as mentioned above, even if you stand back, and consider that many of these professionals had no contact or any activity performed in their academic training, $37.1 \%$ were held in the context of curriculum traineeships, others continued on a voluntary basis in institutions of SS, like the Red Cross, the Portuguese League against Cancer and the Food Bank, among others, but also in associations. The occupational groups with higher expression in this area, by comparison, are social workers, social educators and psychologists. Essentially, the proximity to social problems, the most vulnerable populations or the like by interaction in general, make many of these professionals choose academic courses in the social area.

However, it is important to realize after several years of professional experience and evaluation of the activities performed, the expectations they had when they completed their degree. In general, the evaluation is positive for the situations of all or nearly all the correspondence: $44.5 \%$ to $33.3 \%$ of respondents, this match is partial, and $22.2 \%$ have a positive place. Even more significant is their assessment of the usefulness of knowledge and tasks that were carried out throughout their career. In this case, the situation is clearly favourable to the usefulness of academic training for almost $70 \%$ of respondents.

\subsection{Autonomy and prescription of professional work}

However, considering the preliminary results of this research, autonomy and initiative suggest that they tend to be inclusive of professional practices yet are not entirely consistent. That is, considering the indicators of prior definitions of professional tasks for the organization, recorded changes in the contents of tasks and autonomy for its (re)definition in the next 3-4 years, will permit the identification of two important trends:

1) Most of the tasks prescribed at the time of recruitment which may represent a demand for professionalism, presupposes knowledge of the profile of the tasks, indicating that we are facing the most prestigious professions and / or known. In this case, this would be what Caria (2010) has called the symbolic and cultural autonomy.

2) However, to move forward with this idea of a profession as a body of abstract knowledge and of a technical-

${ }^{7}$ For reasons of time saving for the purpose of this communication, the analysis of some of the discourses of legitimization of the ongoing process of professionalization by social actors involved will not take place. 
scientific nature mainly from academic training, it will also be necessary to check that the changes in the contents of activities would be a result of the intervention of professionals, ie, their autonomy and therefore emphasized in this case, reflective and practical knowledge, ie, the size of technical autonomy (Caria, 2010).

Thus, the trend for the first prescription of tasks at the time of recruitment, seems to be more expressive with economists/Managers and social workers. This greater prescription of tasks is less clear for educators and other social sciences. In intermeddle situations of the prescription of tasks seems to check with sociologists and psychologists. Part of this could be not only the question asked initially of higher degrees of institutionalization of those academic training programmes in Portugal, but especially in the contexts of the organizations in the analysis and hierarchical position taken by professionals. As we saw, we are facing not only TS diverse organizations with their mission and goals, such as the human resources dimension. Moreover, sociologists, unlike social workers, have, for example, come to occupy positions of middle management/leadership during their participation in the organization.

As for the framework in terms of the professional hierarchy, there is also a significant association between those who assume technical roles especially against those who hold positions of leadership or direction. As expected and already mentioned above, the context of lower prescription of tasks at the time of recruitment is felt by those who assume positions of leadership/management, which suggests to some extent, functional content in these relatively new organizational contexts, in the case of integrating the management, planning, among others.

Furthermore, considering the importance of autonomy to change and (re)define the tasks over the next 3 to 4 years, the results tend to reinforce the hierarchical position with management or leadership responsibilities.

This "new" professionalism in the line of thinking of Evetts (2010), which traverses more professional work in an atmosphere of bureaucratic models and managerial models, suggests that many professionals in SC\&H tended to incorporate compliance requirements of goals and results and performance, subject to accountability assessment. We are approaching the point of political autonomy that is expected to gradually incorporate the everyday work of these TS organizations. It will also be based on hybrid nature regarding these situations that, in theory, one can hardly sustain the hegemony of (de)professionalization trends in this field. At least, this line of argument seems insufficient to account for the recomposition of professional practices at the level of SC\&H.

\section{Some final remarks}

In SARTPRO project it is possible to recount some of the central theses that have been suggested throughout this analysis and will certainly support the debate regarding the place of Social Sciences and Humanities in the ongoing process of professionalization, that is, within the its insertion in the division of labor in a capitalist society and the dominant orientation of the neo-liberal policies of public "thing" for the demand of integrated and multidimensional interventions of social problems. In synthetic terms, we were able to meet the following key aspects: 1) relative importance of occupations and organizations in the analysis of autonomy and professional power of 2) "invisible" effects in organizational strategies of professionalization, 3) requirements to adapt to the dynamics of the action of logic that occurs every time, to incorporate more responsibility, autonomy and initiative in daily work; 4) professionalism and training that pass through or contemplating the emerging professional profiles (and corresponding expectations) are not compatible with the role prescriptions, tasks, or services or the incorporation of increasing demands of technicality, together with the mobilization of flexible and proactive behavior and attitudes (eg soft skills, emotional intelligence), 5) professional critique of professionals in Social Sciences and Humanities.

\section{References}

Barbier, J.-M. \& Galatanu, O. (2004). Les savoirs d'action: une mise en mot des compétences. Paris: L'Harmattan.

Boterf, G. (1999). Compétence et navegation professionnele. Editions d'Organisations.

Caria, Telmo (2010). Saberes, Poderes e Autonomia no Trabalho Profissional. Enquadramento teórico e dados preliminares do projecto SARTPRO, documentos de trabalho (policopiado).

Caria, T.(2008). O uso do conceito de cultura na investigação sobre profissões, Análise Social, vol. XLIII (4.º), 2008, 749-773.

Caria, T.; Pereira, F.; Filipe, J. M.; Silva, M. (2005). Saber profissional. Coimbra: Almedina.

Clot, Y \& Faita, D. (2000). Genres et styles en analyse du travail. Concepts et méthodes, Travailler, 4, 7-42.

Clot, Y. \& Béguin, P (2004). L'action située dans le développement de l'activité. @ctivités, II(2), 35-49.

Defourny, J. (2001). L'économie social : enjeux conceptuels, insertion par le travail et services de proximité. Bruxelles: De Boeck \& Larcier s.a..

Evers \& Lavil (eds.) (2004). The Third Sector in Europe. Cheltenham: Edward Elgar.

Evetts, J. (2003). The Sociological Analysis of Professionalism, International Sociology, 18(2), 395-415. 
Fornel, M. (1990). Qu'est-ce qu'un expert? Connaissances procédural et declarative dans l'interaction médicale, Réseaux, 43, 59-80.

Fournier, V. (1999). The appeal to 'professionalism' as a disciplinary mechanism, The Sociological Review, 47(2), 280-307.

Freidson, E. (2001). Professionalism, the Third Logic. The University of Chicago Press.

King, A.(2000). Thinking with Bourdieu against Bourdieu: a 'pratical' critique of the habitus, Sociological Theory, 18 (3), $417-433$.

Lacoste, M. (1990). Interaction et compétences différenciées, Réseaux, 43, 81 - 97

Lester M. S., S. Wojciech Sokolowski (2004). Global Civil Society: Dimensions of the Nonprofit Sector, Volume Two. Kumarian Press, Bloomfield,CT.

Licoppe, Ch. (2008). Dans le carré de l'activité: perspectives internationales sur le travail et l'activité, Sociologie du Travail, 50, $287-302$.

Olgiati, V. (2006). Shiffing heuristic in sociological approach to professional trustworthiness : the sociology of science, Current Sociology, 54, 533-547.

Perrenoud, Ph. (2000). Transférer ou mobiliser ses connaissances? D'une métaphore l'autre: implications sociologiques et pédagogiques. in J. Dolz \& E.

Pfadenhauer, M.(2006). Crisis and decline?: problems of legitimation and loss of trust in modern professionalism, Current Sociology, 54, 565-578.

Sciulli, D. (2005). Continental sociology of professions today: conceptual contributions, Current Sociology, 53, 915-942.

Svensson, L., G. \& Evetts, J. (eds.) (2010). Sociology of Professions. Continental and Anglo-Saxon Traditions, Daidalos. 